\title{
Lifestyle risk factors, obesity and infectious disease mortality in the general population: Linkage study of 97,844 adults from England and Scotland
}

\author{
Mark Hamer,PhD ${ }^{1,2}$ Gary O’Donovan, $\mathrm{PhD}^{3}$ Emmanuel Stamatakis,PhD ${ }^{2,4,5}$
}

${ }^{1}$ School of Sport, Exercise and Health Sciences, Loughborough University, Loughborough LE11 3TU, United Kingdom.

${ }^{2}$ Department of Epidemiology and Public Health, University College London, London WC1E 6BT, United Kingdom.

${ }^{3}$ School of Medicine, Universidad de los Andes, Bogotá, Colombia

${ }^{4}$ Charles Perkins Centre Epidemiology Unit, University of Sydney, Sydney, Australia.

${ }^{5}$ Prevention Research Collaboration, School of Public Health, University of Sydney, Sydney, Australia.

*Correspondence: Prof Mark Hamer, Loughborough University, Loughborough LE11 3TU, United Kingdom. Phone: +44 (0) 1509 228473. Email: m.hamer@lboro.ac.uk

Word count: 3,011

Disclosures: None of the authors have any competing interests to declare.

Funding: Stamatakis is funded by the National Health and Medical Research Council (NHMRC) through a Senior Research Fellowship.

Contributor and guarantor information: Hamer obtained funding, conceptualized and designed the study, performed analyses, drafted the initial manuscript, and approved the final manuscript as submitted. He is the manuscript's guarantor; Stamatakis conceptualized and designed the study, provided statistical input and critical revision of the manuscript, and approved the final manuscript as submitted; O'Donovan conceptualized and designed the study, provided critical revision of the manuscript and approved the final manuscript as submitted. We affirm that the manuscript is an honest, accurate, and transparent account of the study being reported; that no important aspects of the study have been omitted; and that any discrepancies from the study as planned (and, if relevant, registered) have been explained. 


\section{Abstract}

We examined associations between lifestyle variables and infectious disease mortality in a large general population cohort. A sample of 97,844 men and women (aged 47.1 $\pm 17.7 \mathrm{yrs}$; $46.6 \%$ male) recruited from general population, household-based surveys were followed up over mean [SD] 9.4 \pm 4.5 years. Exposure measurements included self-reported physical activity, cigarette smoking, alcohol intake, and objective body mass index and waist to hip ratio. There were 9,027 deaths, of which $14.1 \%$ were attributed to infectious diseases. Compared to physically inactive participants both insufficiently active (Hazard ratio $=0.61$; $95 \% \mathrm{Cl}, 0.50,0.75)$ and sufficiently active (at least $150 \mathrm{~min} / \mathrm{wk}$ moderate - vigorous activity) $(0.60 ; 0.45,0.78)$ was associated with reduced risk of infectious disease mortality in models mutually adjusted for other lifestyle factors. Ex-smokers and current smokers were at increased risk of infectious disease mortality compared with never smoker, with the strongest associations being observed for heavy smoking (>20 cigarettes/day) and pneumonia $(3.30 ; 2.35,4.63)$. Underweight was associated with increased risk of infectious disease mortality $(3.65 ; 2.64,5.06)$ compared with normal weight; the risk of viral infection was lower in overweight $(0.56 ; 0.44,0.72)$ and obesity $(0.39 ; 0.26,0.58)$. Central obesity was, however, related to higher risk of bacterial infections, but only in normal weight centrally obese participants $(1.71 ; 1.10,2.64)$. A physically active lifestyle and lifelong absence from cigarette smoking had protective associations against infectious disease mortality. Obesity has divergent associations dependent on peripheral and visceral fat depots, and the specific outcome.

Key words: Exercise; cigarette smoking; obesity; bacterial infections; virus diseases; mortality 


\section{Introduction}

Infectious disease is becoming an increasing concern particularly in light of escalating microbial resistance..$^{1,2}$ The sepsis incidence rate, for example, continues to rise ${ }^{3}$ and contributes to in excess of 5.3 million deaths per year worldwide. ${ }^{4}$ Sepsis deaths accounted for $7.7 \%$ of all deaths in England. ${ }^{5}$ Antimicrobial medications are often over-prescribed and that has led to increasing problems of antibiotic resistance. Thus, the role of lifestyle for prevention may become increasingly important in coming years. Few studies have assessed the role of multiple lifestyle factors on infection-related mortality at the population level. The majority of existing data have been from small clinical samples or case control studies, ${ }^{6}$ or considered individual lifestyle factors in isolation.

Previous cohort studies have mostly focused on incident pneumonia, ${ }^{7,8}$ pneumonia mortality, ${ }^{9}$ and sepsis outcomes ${ }^{10,11}$ and suggested possible links with physical inactivity, cigarette smoking and obesity. For example, lower levels of physical activity were associated with higher risk of community-acquired sepsis, ${ }^{10}$ and pneumonia ${ }^{7}$ and pneumonia mortality ${ }^{9}$ after accounting for other risk factors. The data on obesity, however, are inconsistent. Various studies have shown obesity to be both a risk factor ${ }^{7}$ and protective ${ }^{9}$ of pneumonia infection, and also to protect against 30-day mortality from pneumonia. ${ }^{12,13}$ In sepsis cases overweight, but not obesity, was associated with lower risk of mortality. ${ }^{6}$ Other cohort data have suggested that overweight and obesity is associated with higher risk of respiratory and skin infections, ${ }^{14}$ higher 30 day mortality risk after detection of blood borne bacterial infection, ${ }^{15}$ whilst protective against viral and fungal infections. ${ }^{14}$ The majority of obesity related infectious disease studies have focused on body mass index (BMI), but not considered central obesity both in itself and in combination with BMI.

The aim of the present study was to examine associations between multiple lifestyle risk factors, obesity (both from BMI and waist measures) and infectious disease mortality in a large general population cohort. 


\section{Materials and methods}

Participants

The Health Survey for England (HSE) and the Scottish Health Survey (SHS) are householdbased surveillance studies. ${ }^{16}$ Participants in the present study took part in one of the following surveys: 1994 (HSE only), 1995 (SHS only), 1997 (HSE only), 1998 (HSE and SHS), 1999 (HSE only), 2003 (HSE and SHS), 2004, 2006, 2008 (HSE only). The proportion of eligible households that took part ranged from $66 \%$ to $81 \%$, and $91.4 \%$ of participants gave consent to prospective linkage with mortality records. A multistage, stratified probability design was used to select participants to be representative of the target populations of the corresponding countries. Stratification was based on geographical areas and not on individual characteristics: postcode (zip code) sectors were selected at the first stage and household addresses selected at the second stage. Local research ethics committees approved all aspects of each survey and all participants gave written informed consent.

\section{Lifestyle variables}

The questionnaires used to assess physical activity are described in detail elsewhere including the validity and reliability. ${ }^{17,18}$ In brief, trained interviewers enquired about the frequency (number of days in the last four weeks) and duration (of an average episode) of participation in: domestic physical activity; light-intensity (slow/average pace) and moderateintensity (fairly brisk/fast pace) walking; and type-specific sports and exercises. For sports and exercises, there was a follow-up question about relative intensity: 'Was the effort of [activity] usually enough to make you out of breath or sweaty?' A compendium ${ }^{19}$ was used to identify moderate- and vigorous-intensity physical activities (MVPA) in the present study: moderate activities were of 3.0-5.9 metabolic equivalents (METs) and vigorous activities were of $\geq 6.0$ METs, where one MET is considered to represent resting energy expenditure. Occupational and routine domestic activities were not included in the present analysis. As used elsewhere ${ }^{20}$ participants were categorised as inactive (not reporting any MVPA), 
insufficiently active ( $>0<150 \mathrm{~min} /$ week MVPA), or sufficiently active (at least $150 \mathrm{~min} /$ week MVPA).

Interviewers also asked about cigarette smoking and alcohol intake. Participants were first asked, 'Have you ever smoked a cigarette, a cigar or a pipe?' If participants answered yes, they were then asked, 'Do you smoke cigarettes at all nowadays?' If yes, they were asked, 'About how many cigarettes a day do you usually smoke on weekdays?' And, 'About how many cigarettes a day do you usually smoke at weekends?' Self-reported smoking has been previously validated in the present sample against objective salivary cotinine data. ${ }^{21}$ Participants were asked if they drank alcohol nowadays, and those who said not were categorised as 'never' drinker or 'ex-drinker' if they used to drink and had stopped. Drinkers were asked, "How often have you had an alcoholic drink of any kind during the last 12 months?"

Height and weight were measured to derive BMI, which was categorised as underweight $\left(<18.5 \mathrm{~kg} \cdot \mathrm{m}^{-2}\right)$, normal weight $\left(18.5-24.99 \mathrm{~kg} \cdot \mathrm{m}^{-2}\right)$, overweight $\left(25-29.99 \mathrm{~kg} \cdot \mathrm{m}^{-2}\right)$, obese stage I $\left(30-34.99 \mathrm{~kg} \cdot \mathrm{m}^{-2}\right)$, and obese stage II $\left(\geq 35 \mathrm{~kg} \cdot \mathrm{m}^{-2}\right) \cdot{ }^{22}$ Waist circumference was recorded twice midway between the iliac crest and lower rib and hip circumference around the widest portion of the buttocks using measuring tape. Central obesity was defined using waist to hip ratio (WHR) World Health Organization criteria (WHR $\geq 0.85$ in women and WHR $\geq 0.90$ in men). ${ }^{23}$

\section{Covariates}

Age and sex were self-reported. Health status was assessed by asking participants whether they had 'any longstanding illness, disability of infirmity.' Socioeconomic status assessed using the Registrar General's classification: professional and managerial occupations; skilled, non-manual occupations; skilled manual occupations; and, routine and manual occupations.

Mortality follow-up 
Participants were flagged by the British National Health Service Central Registry. For participants who survived, the data were censored up to the end of 2009 (SHS) or the first quarter of 2011 (HSE). Diagnoses for the primary cause of death were based on the International Classification of Diseases, Ninth (ICD-9) and Tenth (ICD-10) Revisions. Codes corresponding to infectious diseases were 001- 139 and 480-488 for ICD9 and A00-B99 and J09-J18 for ICD10. We further sub-typed the outcome into bacterial or viral infections, and pneumonia (as the organism was unspecified in all our cases).

Statistical analysis

Cox proportional hazards regression was used to estimate the associations of physical activity, smoking, alcohol and BMI (or WHR) with the risk of infectious disease mortality. The proportional hazards assumption was examined by comparing the cumulative hazard plots grouped on exposure, although no appreciable violations were noted. The timescale was calendar time (months). Models were adjusted for age, sex, social occupational class, longstanding illness and, where appropriate, mutually for cigarette smoking, alcohol, physical activity or BMI. Physical activity analyses were undertaken using several approaches; firstly the data were modelled using categories relevant to the current public health guidelines ${ }^{24}$ in order to optimise the relevance of our results for policy makers; second, we used the data in a continuous format derived from total MET hours in order to examine dose-response relationships in more detail. In a sensitivity analysis, we excluded those who died during the first 24 months of follow-up and those reporting limiting long standing illnesses to explore possible effects of reverse causation. We conducted analyses stratified by the median length of follow up (10.7 yrs; surveys before year 2000 and later survey years 2000 onwards) to examine possible measurement dilution bias in surveys less proximal to the outcome. We also examined combinations of BMI/WHR in relation to infectious disease mortality. All analyses were performed using SPSS version 22 (IBM Inc.). 


\section{Results}

The sample comprised 97,844 participants (aged $47.1 \pm 17.7 \mathrm{yrs} ; 46.6 \%$ male). During 919,949 person years of follow up (mean [SD] 9.4 $\pm 4.5 \mathrm{yr}$; range $0-17$ years) there were 9,027 deaths, of which $14.1 \%$ were attributed to infectious diseases. Participants dying from infectious disease were older than those dying from other causes, contained a greater proportion of ex-smokers, a higher proportion of never and ex-drinkers, were more physically inactive, reported more prevalent disease, and tended to be from lower social classes (Table 1).

Physical activity (both insufficient and sufficiently active) was associated with $\sim 40 \%$ reduced risk of infectious disease mortality in models adjusted for all covariates (Table 2). We explored the dose-response relationship in more detailed sensitivity analyses (Table e1), which suggested there may be an "L"-shaped association between physical activity and risk of infectious disease mortality (i.e, an initial linear reduction in risk with increasing activity, followed by a flattening of the curve at higher levels). Similar patterns emerged when we examined bacterial and viral infections separately, although associations were far weaker for pneumonia mortality (Table 3).

Underweight was associated with increased risk of infectious disease mortality (hazard ratio $[\mathrm{HR}]=3.65,95 \% \mathrm{Cl}, 2.64,5.06)$ compared with normal weight (Table 2), and associations were consistent for both bacterial and viral outcomes, albeit strongest for pneumonia mortality (HR=4.28; 2.56, 7.15) (Table 3). Overweight and stage I obesity were associated with reduced risk of infectious disease mortality compared with normal weight (Table 2) and these associations became marginally stronger for obesity when models were adjusted for all covariates. The protective associations with overweight $(\mathrm{HR}=0.56 ; 0.44,0.72)$ and stage I obesity (HR=0.39; 0.26, 0.58) were particularly strong for viral infections although were absent in the case of bacterial infection (Table 3). We conducted a separate analysis using participants with available data on WHR ( $n=68,205$; events=941). There were no 
associations between central obesity and all infectious disease mortality (fully adjusted $H R=0.96 ; 0.83-1.10)$. We did, however, observe associations for bacterial infection $(H R=1.41 ; 1.01,1.88)$, but not viral $(H R=0.98 ; 0.74,1.30)$ or pneumonia mortality $(H R=0.90$; $0.73,1.11)$. We further examined associations between combinations of BMI categories and central obesity with infectious disease mortality (Table e2) and found increased risk of bacterial infection only in normal weight centrally obese $(H R=1.71 ; 1.10,2.64)$. A reduced risk of viral infection mortality was found in all overweight and obese BMI categories regardless of central obesity.

We observed consistent associations between ex-smokers and current smokers with increased risk of infectious disease mortality compared with never smoker, although no clear dose-response pattern emerged with smoking volume (Table 2). Similar patterns of results emerged in analyses of bacterial and viral infection, although heavy smoking appeared to be a greater risk factor for viral infection $(H R=2.67 ; 1.52,4.11)$ and pneumonia $(H R=3.30 ; 2.35$, 4.63) as oppose to bacterial infections ( $\mathrm{HR}=1.41 ; 0.87,2.31)$ (Table 3$)$. We found no associations between alcohol intake and infectious disease mortality (Table 2), albeit marginally increased risk of pneumonia in ex-drinkers ( $H R=1.50 ; 1.00,2.24)$ (Table 3). In a sub-sample of participants ( $n=48,045$; events $=1058)$ with available data on alcohol volume (calculated by summing the units of each type of beverage and multiplying by the frequency) we did not detect any associations between hazardous or harmful drinking and infectious disease mortality (Table e3).

In sensitivity analyses we removed deaths occurring in the first 2 years of follow up but the results were not appreciably changed (Table e4). We repeated our analyses after removal of participants $(n=37,557)$ who reported "limiting" longstanding illness (Table e5), although results were largely unchanged, albeit some associations were difficult to interpret with limited events in some groups. Although behaviours such as smoking and physical activity remain relatively stable in adulthood, body weight is more likely to fluctuate thus measurement bias is possible for exposures assessed less proximal from the outcome. Thus 
we compared results from the earlier surveys (up to maximum 17 years follow up) with those from later survey years (with up to maximum of 10 years follow up). In general there were few differences (Table e6), except effect estimates for underweight were greater in the more recent surveys with shorter follow up.

\section{Discussion}

The aim of the present study was to examine associations between lifestyle risk factors and infectious disease mortality. The main findings suggest physical activity, never smoking, and overweight/obesity were protective against infectious disease mortality. There have been few community based cohort studies large enough to examine infection related mortality in the general population, and those that have specifically focused on pneumonia ${ }^{7-9}$ or bacterial infections. ${ }^{15}$

Previous work in population cohorts has demonstrated associations between physical activity and lower risk of community acquired pneumonia, ${ }^{7,9}$, sepsis, ${ }^{10,11}$ and 30 day mortality after detection of blood borne bacterial infection. ${ }^{15} \mathrm{~A}$ large amount of work exists on exercise and immunity ${ }^{25}$ that has described a "J" shaped association between exercise and infection with optimal protection at moderate levels of activity. Nevertheless, this body of work has been traditionally based on convenience samples or elite athlete populations with soft end points such as upper respiratory tract infections. ${ }^{26-28}$ Thus, the present study adds substantially by examining associations in a large representative sample with a full spectrum of activity levels and hard endpoint. We did not find the "J" or "U" shaped associations described previously, instead we observed an "L"-shaped pattern, although infectious disease events were limited in the very highly active. The protective associations were seen even at very low levels of activity far below the current guidelines (i.e., between $1-3$ METhr-wk, equivalent to moderate intensity walking for $30 \mathrm{~min}$ per week). Our results are highly congruent with the new 2018 US physical activity guidelines that place increased emphasis 
on physical activity of any intensity and recognise the health benefits of doses below the recommended levels. ${ }^{29}$

Plausible biological mechanisms exist explaining the immunological benefits of exercise, ${ }^{25}$ for example, we previously observed inverse associations between physical activity and circulating inflammatory markers in the present cohort. ${ }^{30} \mathrm{~A}$ body of evidence also suggests that exposure to either acute or chronic exercise significantly augments the immune response to vaccination. ${ }^{31}$

The existing evidence on obesity and infection are equivocal, although data from large cohort studies with substantial follow up has been lacking. Recent studies, ${ }^{9,14,15}$ notable for their large sample sizes and robust outcomes, all demonstrated increased risk of infection in the underweight that is consistent with our data. Inuoe et al. ${ }^{9}$ showed that BMI above 25 kg. $\mathrm{m}^{-2}$ was protective against pneumonia mortality; Harpsøe et al. ${ }^{14}$ suggested that overweight and obesity was associated with higher risk of respiratory and skin infections whilst protective against viral and fungal infections; Paulsen et al. ${ }^{15}$ showed that all levels of BMI defined obesity were associated with higher 30 day mortality risk after detection of blood borne bacterial infection. Thus, our results are largely consistent with these findings suggesting reduced risk of viral infection and pneumonia mortality in overweight/obese when defined from BMI. There are presently limited data on central obesity; recent evidence showed central obesity to be associated with a 1.7 -fold increased risk of sepsis mortality. ${ }^{11}$ We extended these findings by examining the combination of BMI (peripheral obesity) and central obesity, and showed central obesity was associated with increased risk of bacterial infection, particularly in the normal weight centrally obese. The mechanisms behind the obesity paradox are poorly understood, but there may be several explanations. Firstly, infections are often acute illnesses and nutritional reserve provided by excess adiposity may aid survival during a life-threatening period. ${ }^{32}$ We generally observed protective associations with BMI but not WHR, and although it is known that peripheral and visceral fat depots differ in morphology and function ${ }^{33}$ little is known about specific effects on immunity. Second, 
obese participants may have greater contact with primary care, and some data suggest greater use of antibiotics in this group, ${ }^{34}$ which would help treat and diagnose infections more quickly avoiding more serious outcomes such as hospitalisation and death. We did not capture infections treated outside hospital settings thus were unable to explore this issue in more depth. Lastly, there remains the possibility of reverse causation whereby initially obese participants who contract infections lose weight and effectively contaminate the normal weight referent category. ${ }^{35}$ Although our results were unchanged in sensitivity analysis that removed early deaths, we did not have weight histories to properly examine this issue.

Our data showed that heavy smoking was a particularly strong risk factor for pneumonia, which is consistent with increasing recognition of smoking-related lung diseases other than lung cancer and chronic obstructive pulmonary disease. ${ }^{36,37}$ We also observed increased risks of all types of infections in ex-smokers suggesting that tobacco may have long lasting effects. The mechanisms have been largely connected to the inflammatory effects of tobacco smoke ${ }^{36}$ although remain incompletely understood. We found no associations between alcohol consumption and risk of infectious disease that replicates other findings. ${ }^{15}$ The effects of lifestyle risk factors on infection risk may also operate through intermediate disease pathways, such as diabetes and cardiovascular disease, which are associated with both poor lifestyle and increased risk of infections. ${ }^{38,39}$ That the associations between underweight and infection became stronger in surveys more proximal to the outcome suggests a role of underlying diseases that may contribute to both weight loss and increased risk of infections.

The key strengths of this study include the inclusion of a large population sample, validated exposure measures (including objective assessment of obesity), and the ability to examine mortality attributed to both bacterial and viral infections. The main limitation was that we were unable to objectively verify specific infections through positive blood culture and ICD codes are often limited regarding the specific organisms. Nevertheless, the overall proportion of the sample dying from bacterial infection ( $0.4 \%)$ in our study was similar to 
other European data that was verified through blood cultures. ${ }^{15}$ The absence of data on nonmortality related infection is a limitation of the study and our outcome likely reflects the most severe cases. Nevertheless, similar trends have been observed for non-mortality related infection ${ }^{7}$ and infections resulting in death ${ }^{9}$ relative to lifestyle risk factors. Other limitations include the possibility of residual confounding as we lacked complete data on other lifestyle variables (e.g., sedentary behaviour, diet). Physical activity was self-reported thus subject to recall bias, and did not include detailed questions on occupational activity. BMI has been criticised as a measure of obesity. Nevertheless, BMI remains a robust predictor of major causes of death in large scale population studies ${ }^{40}$ and is a useful tool for detecting targeted metabolic traits when compared to direct measures of fat mass (such as Dual-energy X-ray absorptiometry). ${ }^{41}$

In summary, we observed associations between various lifestyle risk factors and infectious disease mortality in a large general population cohort. In light of escalating microbial resistance, healthy lifestyles should be promoted to improve resilience against infectious diseases. These findings will be important to inform future public health policy and assist physicians in clinical decisions to help improve resilience to infection. 


\section{References}

1. Wells V, Piddock LJV. Addressing antimicrobial resistance in the UK and Europe. Lancet Infect Dis 2017; 17(12): 1230-1.

2. Global and Public Health Group. UK 5 Year Antimicrobial Resistance (AMR) Strategy 2013-2018 - third annual progress report, 2016. 2017.

https://assets.publishing.service.gov.uk/government/uploads/system/uploads/attachment da ta/file/662189/UK AMR 3rd annual report.pdf (accessed 24 February 2018).

3. Walkey AJ, Lagu T, Lindenauer PK. Trends in sepsis and infection sources in the United States. A population-based study. Ann Am Thorac Soc 2015; 12(2): 216-20.

4. Fleischmann C, Scherag A, Adhikari NK, et al. Assessment of Global Incidence and Mortality of Hospital-treated Sepsis. Current Estimates and Limitations. Am J Respir Crit Care Med 2016; 193(3): 259-72.

5. McPherson D, Griffiths C, Williams M, et al. Sepsis-associated mortality in England: an analysis of multiple cause of death data from 2001 to 2010. BMJ Open 2013; 3(8).

6. Wang S, Liu X, Chen Q, Liu C, Huang C, Fang X. The role of increased body mass index in outcomes of sepsis: a systematic review and meta-analysis. BMC Anesthesiol 2017; 17(1): 118.

7. Baik I, Curhan GC, Rimm EB, Bendich A, Willett WC, Fawzi WW. A prospective study of age and lifestyle factors in relation to community-acquired pneumonia in US men and women. Arch Intern Med 2000; 160(20): 3082-8.

8. Kornum JB, Norgaard M, Dethlefsen C, et al. Obesity and risk of subsequent hospitalisation with pneumonia. Eur Respir J 2010; 36(6): 1330-6.

9. Inoue $\mathrm{Y}$, Koizumi $\mathrm{A}, \mathrm{Wada} \mathrm{Y}$, et al. Risk and protective factors related to mortality from pneumonia among middleaged and elderly community residents: the JACC Study. $J$ Epidemiol 2007; 17(6): 194-202.

10. Wang HE, Baddley J, Griffin RL, et al. Physical inactivity and long-term rates of community-acquired sepsis. Prev Med 2014; 65: 58-64. 
11. Williams PT. Inadequate exercise as a risk factor for sepsis mortality. PLoS One 2013; 8(12): e79344.

12. Corrales-Medina VF, Valayam J, Serpa JA, Rueda AM, Musher DM. The obesity paradox in community-acquired bacterial pneumonia. Int $J$ Infect Dis 2011; 15(1): e54-7. 13. Singanayagam A, Singanayagam A, Chalmers JD. Obesity is associated with improved survival in community-acquired pneumonia. Eur Respir J 2013; 42(1): 180-7. 14. Harpsoe MC, Nielsen NM, Friis-Moller N, et al. Body Mass Index and Risk of Infections Among Women in the Danish National Birth Cohort. Am J Epidemiol 2016; 183(11): 1008-17.

15. Paulsen J, Askim A, Mohus RM, et al. Associations of obesity and lifestyle with the risk and mortality of bloodstream infection in a general population: a 15-year follow-up of 64 027 individuals in the HUNT Study. Int J Epidemiol 2017; 46(5): 1573-81.

16. Mindell J, Biddulph JP, Hirani V, et al. Cohort profile: the health survey for England. Int J Epidemiol 2012; 41(6): 1585-93.

17. Stamatakis E, Hillsdon M, Primatesta P. Domestic physical activity in relationship to multiple CVD risk factors. Am J Prev Med 2007; 32(4): 320-7.

18. Scholes S, Coombs N, Pedisic Z, et al. Age- and sex-specific criterion validity of the health survey for England Physical Activity and Sedentary Behavior Assessment Questionnaire as compared with accelerometry. Am J Epidemiol 2014; 179(12): 1493-502. 19. Ainsworth BE, Haskell WL, Herrmann SD, et al. 2011 Compendium of Physical Activities: a second update of codes and MET values. Medicine and science in sports and exercise $2011 ;$ 43(8): 1575-81.

20. O'Donovan G, Lee I-M, Hamer M, Stamatakis E. Association of "Weekend Warrior" and Other Leisure Time Physical Activity Patterns With Risks for All-Cause, Cardiovascular Disease, and Cancer Mortality. JAMA Internal Medicine. 2017;177(3):335-342.

21. Hamer M, Stamatakis E, Kivimaki M, Lowe GD, Batty GD. Objectively measured secondhand smoke exposure and risk of cardiovascular disease: what is the mediating role of inflammatory and hemostatic factors? J Am Coll Cardiol 2010; 56(1): 18-23. 
22. World Health Organisation. Physical status: the use and interpretation of anthropometry. Report of a WHO Expert Committee. World Health Organ Tech Rep Ser 1995; 854: 1-452.

23. World Health Organisation. Waist circumference and waist-hip ratio, Report of a WHO expert consultation, Geneva, 8-11 December 2008. 2011.

https://www.who.int/nutrition/publications/obesity/WHO report waistcircumference and wai sthip ratio/en/ (accessed 7 February 2019).

24. World Health Organisation. Global recommendations on physical activity for health. 2010. http://www.who.int/dietphysicalactivity/factsheet_recommendations/en/ (accessed January 2018)

25. Schwellnus M, Soligard T, Alonso JM, et al. How much is too much? (Part 2) International Olympic Committee consensus statement on load in sport and risk of illness. $\mathrm{Br}$ J Sports Med 2016; 50(17): 1043-52.

26. Spence L, Brown WJ, Pyne DB, et al. Incidence, etiology, and symptomatology of upper respiratory illness in elite athletes. Medicine and science in sports and exercise 2007; 39(4): 577-86.

27. Matthews CE, Ockene IS, Freedson PS, Rosal MC, Merriam PA, Hebert JR. Moderate to vigorous physical activity and risk of upper-respiratory tract infection. Medicine and science in sports and exercise 2002; 34(8): 1242-8.

28. Nieman DC, Henson DA, Austin MD, Sha W. Upper respiratory tract infection is reduced in physically fit and active adults. Br J Sports Med 2011; 45(12): 987-92.

29. Physical Activity Guidelines Advisory Committee. Physical Activity Guidelines Advisory Committee Scientific Report. 2018. https://health.gov/paguidelines/secondedition/report/ (accessed 7 February 2019).

30. Hamer M, Stamatakis E. Physical activity and risk of cardiovascular disease events: inflammatory and metabolic mechanisms. Medicine and science in sports and exercise 2009; 41(6): 1206-11. 
31. Pascoe AR, Fiatarone Singh MA, Edwards KM. The effects of exercise on vaccination responses: a review of chronic and acute exercise interventions in humans. Brain Behav Immun 2014; 39: 33-41.

32. Niedziela J, Hudzik B, Niedziela N, et al. The obesity paradox in acute coronary syndrome: a meta-analysis. Eur J Epidemiol 2014; 29(11): 801-12.

33. Gesta S, Tseng YH, Kahn CR. Developmental origin of fat: tracking obesity to its source. Cell 2007; 131(2): 242-56.

34. Wang Y, Chen Y. Increased Risk of Bacterial Infections among the Obese with Chronic Diseases. J Nutr Health Aging 2015; 19(5): 595-600.

35. Stokes A, Preston SH. Revealing the burden of obesity using weight histories. Proceedings of the National Academy of Sciences of the United States of America 2016; 113(3): 572-7.

36. Crotty Alexander LE, Shin S, Hwang JH. Inflammatory Diseases of the Lung Induced by Conventional Cigarette Smoke: A Review. Chest 2015; 148(5): 1307-22.

37. Carter BD, Abnet CC, Feskanich D, et al. Smoking and mortality--beyond established causes. N Engl J Med 2015; 372(7): 631-40.

38. Wang HE, Shapiro NI, Griffin R, Safford MM, Judd S, Howard G. Chronic medical conditions and risk of sepsis. PLoS One 2012; 7(10): e48307.

39. Rao Kondapally Seshasai S, Kaptoge S, Thompson A, et al. Diabetes mellitus, fasting glucose, and risk of cause-specific death. N Engl J Med 2011; 364(9): 829-41. 40. Global BMI Mortality Collaboration, Di Angelantonio E, Bhupathiraju Sh N, et al. Body-mass index and all-cause mortality: individual-participant-data meta-analysis of 239 prospective studies in four continents. Lancet 2016; 388(10046): 776-86.

41. Bell JA, Carslake D, O'Keeffe LM, et al. Associations of Body Mass and Fat Indexes With Cardiometabolic Traits. J Am Coll Cardiol 2018; 72(24): 3142-54. 
Table 1. Baseline characteristics according to death status

\begin{tabular}{|c|c|c|c|}
\hline Variable at baseline & Alive & $\begin{array}{l}\text { Death from other } \\
\text { causes }\end{array}$ & $\begin{array}{l}\text { Death from } \\
\text { infectious disease }\end{array}$ \\
\hline $\mathrm{N}$ & 88817 & 7753 & 1274 \\
\hline Age (yrs, SD) & $44.9 \pm 16.1$ & $66.9 \pm 13.1$ & $73.0 \pm 10.9$ \\
\hline Sex (\% men) & 46.1 & 52.3 & 51.1 \\
\hline $\begin{array}{l}\text { Cigarette Smoking (\%) } \\
\text { Never } \\
\text { Ex-smoker } \\
\text { Light, }<10 / d \\
\text { Medium,10-19/d } \\
\text { Heavy, } \geq 20 / d\end{array}$ & $\begin{array}{l}49.4 \\
23.7 \\
7.5 \\
11.0 \\
8.5\end{array}$ & $\begin{array}{l}31.9 \\
38.8 \\
5.8 \\
11.0 \\
12.4\end{array}$ & $\begin{array}{l}31.8 \\
45.2 \\
7.7 \\
8.1 \\
7.2 \\
\end{array}$ \\
\hline $\begin{array}{l}\text { Alcohol, frequency (\%) } \\
\text { Never } \\
\text { Ex-drinker } \\
<\text { monthly } \\
1-2 \text { / month } \\
1-4 \text { /week } \\
\geq 5 \text { /week }\end{array}$ & $\begin{array}{l}6.3 \\
3.5 \\
13.6 \\
13.2 \\
46.2 \\
17.2 \\
\end{array}$ & $\begin{array}{l}6.6 \\
8.1 \\
17.5 \\
10.5 \\
33.9 \\
23.4\end{array}$ & $\begin{array}{l}9.3 \\
9.2 \\
19.2 \\
9.5 \\
29.7 \\
23.1\end{array}$ \\
\hline $\begin{array}{l}\text { Physical activity (\%) } \\
\text { Inactive } \\
\text { Insufficiently active } \\
\text { Sufficiently active }\end{array}$ & $\begin{array}{l}47.9 \\
29.4 \\
22.7\end{array}$ & $\begin{array}{l}80.8 \\
12.7 \\
6.5\end{array}$ & $\begin{array}{l}86.9 \\
8.7 \\
4.4\end{array}$ \\
\hline $\begin{array}{l}\text { Body mass index category } \\
\text { Underweight } \\
\text { Normal } \\
\text { Overweight } \\
\text { Stage I obese } \\
\text { Stage Il obese }\end{array}$ & $\begin{array}{l}0.7 \\
39.4 \\
38.6 \\
15.3 \\
5.9 \\
\end{array}$ & $\begin{array}{l}1.4 \\
34.5 \\
40.8 \\
17.1 \\
6.1 \\
\end{array}$ & $\begin{array}{l}3.1 \\
38.0 \\
39.8 \\
14.2 \\
4.9 \\
\end{array}$ \\
\hline $\begin{array}{l}\text { Longstanding illnesses } \\
(\%)\end{array}$ & 41.1 & 67.6 & 72.8 \\
\hline $\begin{array}{l}\text { Professional occupations } \\
(\%)\end{array}$ & 4.9 & 3.1 & 2.1 \\
\hline
\end{tabular}


Table 2. Lifestyle risk factors and infectious disease mortality $(N=97,844)$

\begin{tabular}{|c|c|c|c|c|}
\hline Risk factor & $\mathbf{N}$ & Deaths & $\begin{array}{c}\text { Model } 1 \\
\text { Hazard Ratio } \\
(95 \% \mathrm{Cl})\end{array}$ & $\begin{array}{c}\text { Model } 2 \\
\text { Hazard Ratio } \\
(95 \% \mathrm{Cl})\end{array}$ \\
\hline \multicolumn{5}{|l|}{ Physical activity } \\
\hline Inactive & 49,960 & 1107 & 1.00 (Ref) & 1.00 (Ref) \\
\hline Insufficient & 27,207 & 107 & $0.54(0.34,0.56)$ & $0.61(0.50,0.75)$ \\
\hline Sufficiently active & 20,677 & 56 & $0.51(0.39,0.67)$ & $0.60(0.45,0.78)$ \\
\hline \multicolumn{5}{|l|}{$\begin{array}{l}\text { Body mass index } \\
\text { category }\end{array}$} \\
\hline Underweight & 805 & 40 & $4.07(2.94,5.62)$ & $3.65(2.64,5.06)$ \\
\hline Normal & 38,193 & 484 & 1.00 (Ref) & 1.00 (Ref) \\
\hline Overweight & 37,969 & 507 & $0.71(0.63,0.80)$ & $0.72(0.63,0.81)$ \\
\hline Stage I obese & 15,125 & 181 & $0.72(0.60,0.85)$ & $0.69(0.58,0.82)$ \\
\hline Stage II obese & 5,752 & 62 & $0.92(0.70,1.20)$ & $0.82(0.63,1.07)$ \\
\hline \multicolumn{5}{|l|}{$\begin{array}{l}\text { Cigarette } \\
\text { smoking }\end{array}$} \\
\hline Never & 46,713 & 405 & 1.00 (Ref) & 1.0 (Ref) \\
\hline Ex-smoker & 24,604 & 576 & $1.46(1.28,1.67)$ & $1.46(1.28,1.67)$ \\
\hline Current, $<10 / d$ & 7,235 & 98 & $2.57(2.06,3.20)$ & $2.26(1.81,2.82)$ \\
\hline Current, 10-19/d & 10,720 & 103 & $2.32(1.86,2.89)$ & $1.91(1.53,2.39)$ \\
\hline Current, $\geq 20 / d$ & 8,565 & 92 & $2.96(2.34,3.74)$ & $2.43(1.91,3.08)$ \\
\hline \multicolumn{5}{|l|}{$\begin{array}{l}\text { Alcohol } \\
\text { frequency }\end{array}$} \\
\hline Never & 6,190 & 119 & 1.00 (Ref) & 1.0 (Ref) \\
\hline Ex-drinker & 3,831 & 117 & $1.46(1.18,1.88)$ & $1.24(0.96,1.61)$ \\
\hline$<$ monthly & 13,614 & 244 & $0.99(0.80,1.23)$ & $0.96(0.77,1.19)$ \\
\hline $1-2 /$ month & 12,624 & 121 & $0.84(0.65,1.08)$ & $0.88(0.68,1.14)$ \\
\hline $1-4 /$ week & 43,859 & 378 & $0.86(0.70,1.06)$ & $0.89(0.72,1.10)$ \\
\hline$\geq 5$ /week & 17,303 & 294 & $0.91(0.73,1.13)$ & $0.94(0.76,1.19)$ \\
\hline
\end{tabular}

Model 1: adjusted for age and sex

Model 2: adjusted for age, sex, longstanding illness, social occupational status, and mutually for physical activity, BMI category, cigarette smoking, alcohol. 
Table 3. Lifestyle risk factors and infectious disease mortality stratified by bacterial or viral origin.

\begin{tabular}{|c|c|c|c|}
\hline Risk factor & $\begin{array}{c}\text { Bacterial } \\
\text { Hazard Ratio } \\
(95 \% \mathrm{Cl}) \\
\text { (369 deaths) }\end{array}$ & $\begin{array}{c}\text { Viral } \\
\text { Hazard Ratio } \\
(95 \% \mathrm{Cl}) \\
\text { (326 deaths) }\end{array}$ & $\begin{array}{c}\text { Pneumonia } \\
\text { Hazard Ratio } \\
(95 \% \mathrm{Cl}) \\
\text { (579 deaths) }\end{array}$ \\
\hline \multicolumn{4}{|l|}{ Physical activity } \\
\hline Inactive & 1.00 (Ref) & 1.00 (Ref) & 1.00 (Ref) \\
\hline Insufficient & $0.57(0.39,0.82)$ & $0.36(0.21,0.60)$ & $0.80(0.61,1.04)$ \\
\hline Sufficiently active & $0.46(0.27,0.79)$ & $0.48(0.26,0.88)$ & $0.76(0.52,1.11)$ \\
\hline \multicolumn{4}{|l|}{$\begin{array}{l}\text { Body mass index } \\
\text { category }\end{array}$} \\
\hline Underweight & $2.34(1.09,5.03)$ & $3.82(2.30,6.35)$ & $4.28(2.56,7.15)$ \\
\hline Normal & 1.00 (Ref) & 1.00 (Ref) & 1.00 (Ref) \\
\hline Overweight & $0.86(0.68,1.09)$ & $0.56(0.44,0.72)$ & $0.73(0.61,0.88)$ \\
\hline Stage I obese & $0.91(0.67,1.24)$ & $0.39(0.26,0.58)$ & $0.75(0.58,0.96)$ \\
\hline Stage II obese & $0.91(0.56,1.48)$ & $0.76(0.47,1.23)$ & $0.81(0.53,1.24)$ \\
\hline \multicolumn{4}{|l|}{$\begin{array}{l}\text { Cigarette } \\
\text { Smoking }\end{array}$} \\
\hline Never & 1.00 (Ref) & 1.0 (Ref) & 1.0 (Ref) \\
\hline Ex-smoker & $1.43(1.12,1.82)$ & $1.52(1.17,1.99)$ & $1.45(1.19,1.76)$ \\
\hline Light, $<10 / d$ & $2.49(1.68,3.68)$ & $2.58(1.70,3.93)$ & $1.95(1.37,2.78)$ \\
\hline Medium,10-19/d & $1.85(1.24,2.76)$ & $2.17(1.43,3.29)$ & $1.83(1.29,2.61)$ \\
\hline Heavy, $\geq 20 / d$ & $1.41(0.87,2.31)$ & $2.67(1.51,4.11)$ & $3.30(2.35,4.63)$ \\
\hline \multicolumn{4}{|l|}{$\begin{array}{l}\text { Alcohol } \\
\text { frequency }\end{array}$} \\
\hline Never & 1.00 (Ref) & 1.00 (Ref) & 1.00 (Ref) \\
\hline Ex-drinker & $1.10(0.68,1.77)$ & $1.11(0.68,1.80)$ & $1.50(1.00,2.24)$ \\
\hline$<$ monthly & $0.83(0.55,1.25)$ & $0.87(0.58,1.31)$ & $1.14(0.81,1.61)$ \\
\hline $1-2 /$ month & $0.72(0.45,1.16)$ & $0.68(0.41,1.14)$ & $1.17(0.80,1.72)$ \\
\hline $1-4 /$ week & $0.77(0.52,1.14)$ & $0.87(0.58,1.29)$ & $1.02(0.73,1.43)$ \\
\hline$\geq 5$ /week & $0.81(0.54,1.22)$ & $0.85(0.56,1.28)$ & $1.12(0.80,1.59)$ \\
\hline
\end{tabular}

Models adjusted for age, sex, longstanding illness, social occupational status, and mutually for physical activity, BMI category, cigarette smoking, alcohol. 